\title{
FUTURE IN CHILDREN'S HANDS - INFORMAL EDUCATION AS A TOOL FOR SOCIAL CHANGE. THE HANDS ON! 2017 CONFERENCE IN THE CZECH REPUBLIC

\section{DENISA BREJCHOVÁ}

"The purpose of education and wisdom is that one is able to look ahead and see clearly the path through life, walk it carefully, remember the past, be aware of the present and foresee the future."

John Amos Comenius

How we can help present-day children to grasp "the world" and raise a generation with healthy attitude to their own identity and history? Can we use the didactic potential of cultural institutions and involve them in the education process? Are the Czech institutions able to compete internationally?

The role of museums in society is unique. People collect and keep various objects from time immemorial. In today's world there are about forty thousand museums, which keep millions of collection objects. A museum is a non-profit, permanent institution in the service of society and its development, open to the public, which acquires, conserves, researches, communicates and exhibits the tangible and intangible heritage of humanity and its environment for the purposes of study, education and enjoyment. ${ }^{1}$ Education and enjoyment... The purpose of existence of museums and galleries thus does not consist in only the collections themselves, but also in acquiring knowledge on the world outside, satisfying the urge to search and find answers to

1 Definition by the International Council of Museums ICOM.

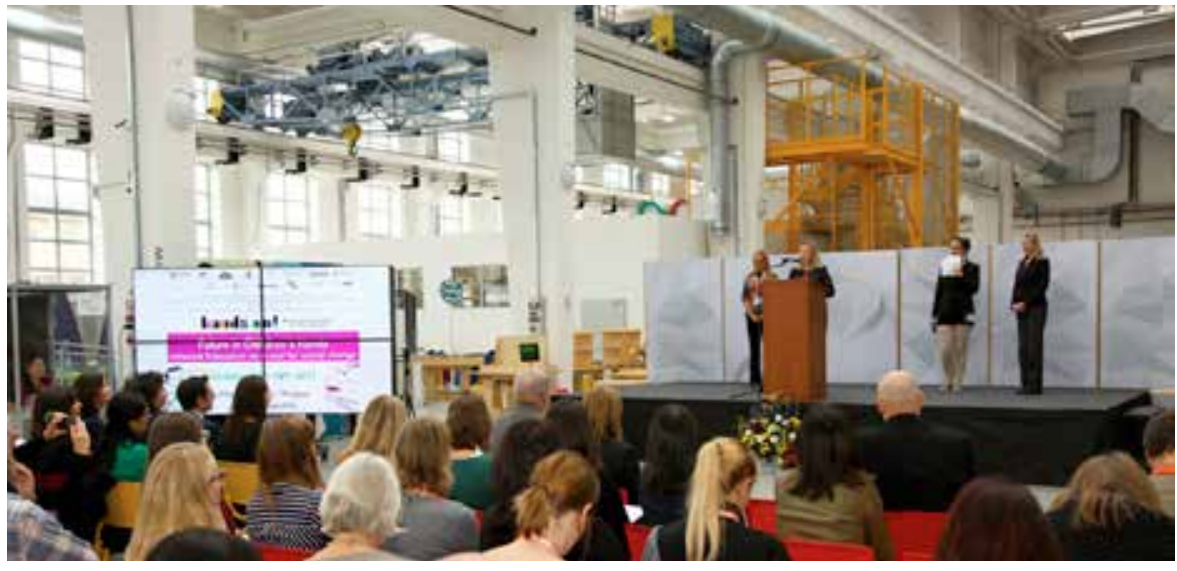

Photo: Martin Čarek, Czech Association of Museums and Galleries, 2017.

basic questions about the purpose of human life and contributing to public education, mainly of children. Cultural institutions must be able to function as an alternative place of education and at the same time build the attitude to historical values and museums in general among pupils. An indispensable part of a modern museum is represented by interactive exhibitions based on the so-called "hands on" principle (touching allowed). At the same time, however, it is necessary to ensure that visitors show respect to original collection objects, which make memory institutions unique. But despite this, or just because of this, a museum, a gallery or a monument are the most suitable places for extracurricular education. It is beyond doubt that our future, and therewith also the future of cultural institutions, rests in the hands of children. It depends (also) on us whether the present-day children will some day create a society with deep relationship to history, art or culture. Especially in the present, when we find ourselves in the centre of big changes, migrations and mingling of influences, the building of the relationship to our own past and to the present uniqueness represents the cornerstone for a sustainable future of a nation.

Social engagement is own to all museums, no matter in which part of the world they are situated. The conditions of fulfilling this idea are of course very different, determined by the historical development.

Europe split after the World War II. Cultural institutions also developed in a different way after 1945 . While the museums in the western part of Europe built their relationship 


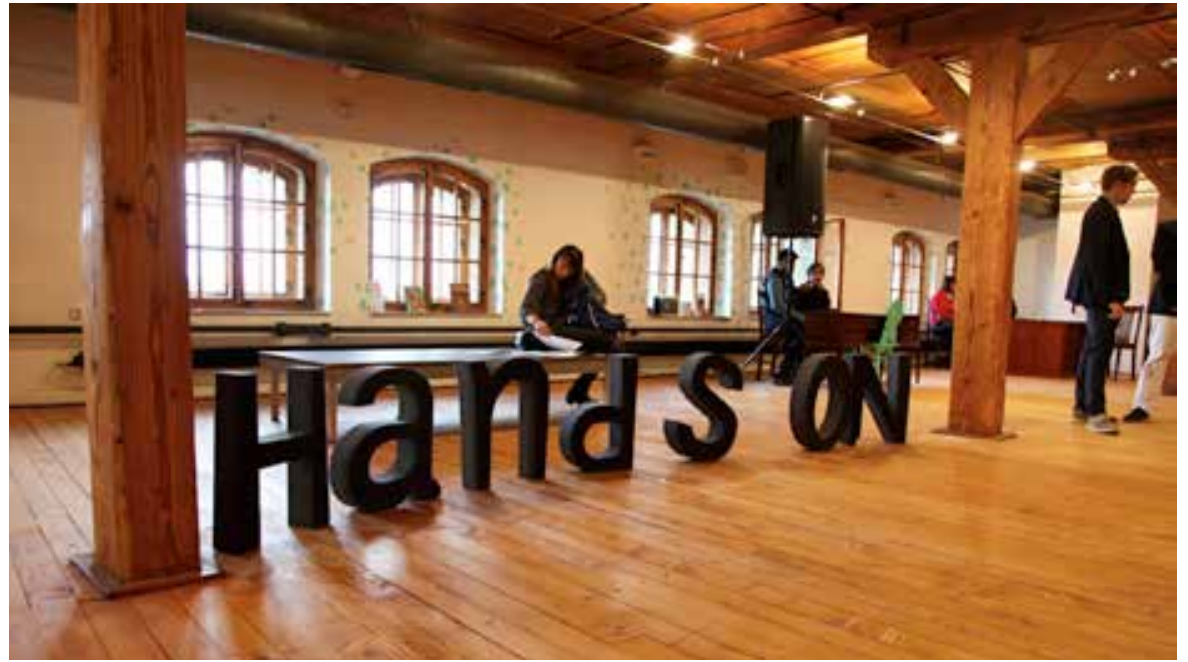

Photo: Martin Čarek, Czech Association of Museums and Galleries, 2017

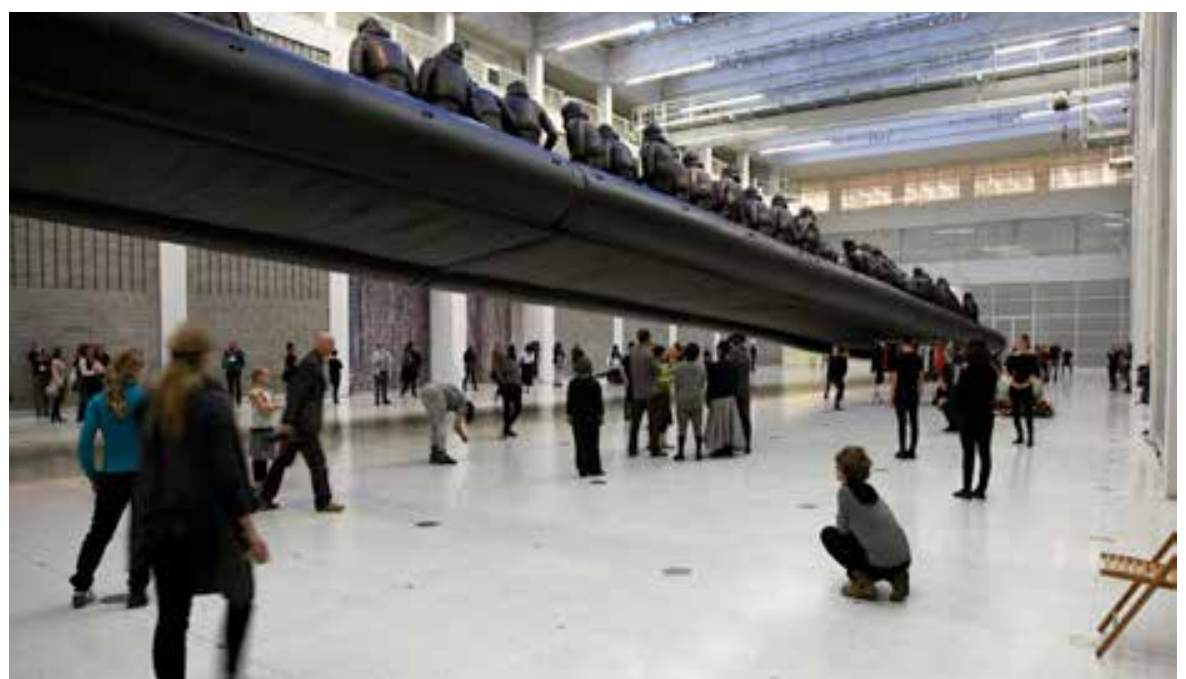

Photo: Martin Čarek, Czech Association of Museums and Galleries, 2017.

with visitors and searched for the most suitable forms of presentation of their collections, Czech museums often had to fulfil tasks in the field of culture-educational work and propaganda. A new era of Czech museums began in the 1990s. Many differences between the "East" and the "West" wiped away in the past twenty years, but some specifics still survive. One of the major deficiencies in the activity of Czech museums persists in the area of museum pedagogy and informal education, even though a lot was already done for support of professional development, consolidation of methodological base or development of professional standards. But the biggest challenges are still ahead. A healthy and conceptual development of museum pedagogy as a discipline requires not only an intensive and systematic cooperation with Ministry of Education, Youth and Sports and Ministry of Culture of the Czech Republic, but also a connection with international platform. It is necessary to look at the problem of informal education in a wider context and not to limit it only to museum pedagogical activities, but establish a true interdisciplinary cooperation (museums, galleries, science centres, universities, etc.) both at national and at international level. Through the exchange of experience and sharing of ideas among colleagues, each individual can contribute to the professional portfolio of this discipline. Our aim should not be to emphasize the differences between "Eastern" and "Western" Europe, but rather build the relationship to own uniqueness and search for common ways which bring innovative approaches and new trends to both parties involved.

This year, the Czech and Slovak museum educators had the possibility to take part in an important international event and compare their experiences with colleagues from all over the world. In October 2017, the Czech Republic hosted an international conference titled Future in Children's Hands - Informal Education as a Tool for Social Change.

The conference was held under the auspices of the Hands On! organisation, which was founded more than twenty years ago on the initiative of European museum directors as an informal network of institutions promoting children's museums all over the world. Since 2015, the office of this association is located in Graz, Austria. Currently the association consists of large as well as smaller organisations from 40 countries. The common goal of these "hands on" institutions is the effort to present the museums and galleries to young visitors as attractive and friendly places stimulating their curiosity and creativity, places where they can have fun and at the same time learn something new in an entertaining and easy way. To this organisation, all children's museums and institutions are equally important, no matter if they build their own collections or not. The association offers statistic data to its members, follows up existing and new trends 
in extracurricular education and provides information about EU funds and projects. As an appreciation of innovative and inspiring approaches in the field of permanent museum exhibitions, the Hands On! organisation awards yearly the Children in Museums Award. The most important activity consists in the above-mentioned professional international conferences, which are held every two years in major European cities.

In 2017, the collective of host countries was extended by the Czech Republic - a country in the heart of Europe, a historical crossing of cultures, a place where political, economic and artistic influences, including the pedagogical trends, have always melted together. It also is the birth place of the founder of European pedagogy, author of the most significant didactic work Orbis Sensualium Pictus and father of the principle "learning through play", which is literally the base of the "hands on" approach, a patriot, expellee, European - John Amos Comenius. These specifics were reflected in the content of individual lectures. Each of three host cities accentuated its own key topic: Pilsen had children vs. digital technologies, Písek discussed children vs. cultural heritage, and finally Prague presented children vs. political and social issues. The complete content of all lectures cannot be presented here in detail - some of the presentations were very inspiring, others caused controversies - but all of them touched problems which are own to all those who are working in museums or other cultural institutions, no matter from which part of the world they come. The inclusion of minorities in the society through the medium of cultural institutions was treated by Andy Ackerman, Director of the Children's Museum of Manhattan, USA, and Elisabeth Menasse, Director of the ZOOM Children's Museum in Vienna, Austria (both institutions created permanent exhibitions for children about Islamic culture). The Czech Republic was represented for example by Jiří Fajt, Director General of the National Gallery in Prague, or MUDr. Martin Stránský, whose presentation about the impact of digital media on the evolution of child's brain raised emotions and many controversies. About the role of museums from the aspect of global economy spoke Charles Seaford, Director of An Economy that Works and consultant of World Future Council in United Kingdom. The closing lecture by Andreas Heinecke, social entrepreneur and creator of the "Dialog in the Dark" project (an exhibition dedicated to blind and weak-eyed), was dealing with the conflict between protection of social values and struggle for own survival, which is currently own to most museums.

The conference of course did not answer all the questions posed. However, it offered an important opportunity to meet, think about problems, establish professional contacts and hold inspiring discussions. In events like this you find out that your colleagues from the opposite side of the globe encounter the same problems, that you are not alone and that your work makes sense.

\section{DENISA BREJCHOVÁ \\ West Bohemia Museum in Pilsen, Czech Republic}

